\title{
The impact of workplace spirituality on work-based learners
}

\section{Individual and organisational level perspectives}

\author{
Scott Foster \\ PhD Programme, Liverpool John Moores University, Liverpool, UK, and \\ Anna Foster \\ School of Environment, Education and Development, \\ University of Manchester, Manchester, UK
}

\begin{abstract}
Purpose - The purpose of this paper is to contribute to the emerging spirituality debate with the aim of generating and sustaining tolerance for spirituality in the workplace, with a specific focus upon the impact this can have upon work-based learners. "Spirituality" is gaining impetus worldwide as a growing number of organisations are proactively accommodating their multi-ethnic and multi-faith workforce by adapting their policies to meet employees' spiritual needs. As yet in the UK, the majority of organisations fail to recognise neither the basic spiritual well-being of their employees nor the impact this can have upon work-based learning processes.

Design/methodology/approach - This study adopts a quantitative approach with questionnaires distributed to a multi-national retail UK-based organisation with an ethnically diverse national workforce. The study was tested by collecting data from managers and employees of this large, multi-million pound retail chain organisation in the UK, consisting of 55 stores and 1,249 employees, in order to gather employees' perceptions on spirituality within their place of work regarding policies, communication and perceived source of conflict.

Findings - The results revealed that the majority of employees deemed spirituality was not something they felt comfortable discussing or appropriate to practice within the workplace and there were no clear policies and procedures in place to support either management or employees.

Research limitations/implications - This paper highlights areas for further research in the broad professional areas of spirituality in relation to organisational approaches to work-based learning. The research is from one organisation and utilising one method - qualitative research would add depth to the knowledge. Practical implications - This paper highlights areas for further research in the broad professional areas of spirituality in relation to organisational approaches to work-based learning.

Originality/value - Employee spiritual well-being is under-researched and overlooked by organisations. Changing the current spiritual intransigence is long overdue as employees' spiritual fulfilment leads to high-trust relationships in the workplace and can further support those engaged in work-based learning.

Keywords Religion, Well-being, Culture, Spirituality, Work-based learning, Professional ethics, Business, Human resource development, Moral issues, Organizational values

Paper type Research paper
\end{abstract}

\section{Introduction}

The late and the early twenty-first centuries have seen a growing interest in spirituality in general and its role in the workplace in particular (Wagner-Marsh and Conley, 1999; Bell and Burack, 2001; Ramdass and Van Tonder, 2009; Sedikides, 2010) and whilst organisations are attempting to understand the complexity of spirituality, Deshpande (2012) warns that

(C) Scott Foster and Anna Foster. Published in Journal of Work-Applied Management. Published by Emerald Publishing Limited. This article is published under the Creative Commons Attribution (CC BY 4.0) licence. Anyone may reproduce, distribute, translate and create derivative works of this article (for both commercial and non-commercial purposes), subject to full attribution to the original publication and authors. The full terms of this licence may be seen at http://creativecommons.org/licences/by/4.0/legalcode

Received 7 June 2019 Revised 8 June 2019 17 June 2019 Accepted 18 June 2019 
JWAM

11,1

workplace spirituality is a prominent reality in the current business environment and it should not be dismissed. However, despite this growing interest in spirituality and its place within the organisation, the concept remains undertheorised (Dirkx, 2013). Scholars have not significantly come up with a greater reductive explanation for the phenomena, to the extent that the concept even lacks a generally accepted definition (Alas and Mousa, 2016; Hassan, 2016). The literature is dominated by speculative discussion, fragmentation, dearth and incomprehensibility, an American perspective and a marked lack of empirical data, especially quantitative research (Ali et al., 2015; Khaled et al., 2012). Matthieu (2017) goes on to note that, much of this work is in fact, useful and thought provoking, but it needs to be extended with experience or empirical data to prevent theories being remote from the phenomenon they intend to describe. Therefore, this paper aims to contribute to the small corpus of empirical work on spirituality by examining whether:

- recognition of spirituality is embedded in organisational culture through dialogue, policies and procedures;

- spirituality is a source of conflict within the workplace;

- employees feel unable to express and observe their spiritual beliefs; and

- further consideration is needed to the dimensions of spirituality in relation to workbased learners.

\section{Perspectives on spirituality}

Given the highly subjective nature of what spirituality is and of what it is comprised, it is not surprising the phenomena lacks a universally accepted definition. Consequently, the literature on the topic is characterised by varying degrees of emphasis, focus, components and levels of analysis. In general, terms, spirituality has traditionally been viewed dichotomously as essentially a religious phenomenon in the search for the sacred, or as a humanist phenomenon with no religious connotations whatsoever. Historically, spirituality was rooted in religion, and this belief still commands powerful support (Cavanagh, 1999). However, as Miller and Thoresen (2003) acknowledge, religion is to spirituality as medicine is to health, and although religion is only one expression of spirituality, it is an important one. As a consequence, there is a strong focus on the religious interpretation of spirituality in the literature (Mitchell, 2013).

A countervailing force to the religious tradition of spirituality was the European Enlightenment of the late seventeenth and eighteenth centuries, which made many western societies distrustful of religion, viewing it as being characterised by superstition and opposition to rationality (Baker et al., 2011). The enlightenment was, of course, underpinned and informed by humanism, and humanism forms the second perspective on spirituality. This humanistic view of spirituality with few or no religious connotations (Fisher, 2011) can include acts of compassion; including work, deep reflection and contemplation, enjoying nature, literature and poetry, and engaging in creative activities such as art, cookery and gardening. It may also comprise of maintaining stable family relations friendships, especially those involving high levels of intimacy and trust, and participation in group or team sports and other recreational activities.

\section{Spirituality in the workplace}

In a time of public debate about spiritual tolerance and cultural freedom in a multi-cultural society, it is important to gain a true understanding of how differing religions and spiritualties can manifest within organisations (Wall and Knights, 2013; Stokes, 2011). Hofstede (1997) claims that it is important to gain a true understanding of how differing 
religions and spiritualties can manifest themselves within an organisation. Furthermore, as Wall (2017, p. 304) suggests, "the UK faces a time of huge transition and transformation. We believe we must work towards putting people much more at the heart of business thinking and practice". Yet, given the paucity of empirical research into the subject of spirituality, this is often easier said than done. Some organisations, however, such as Coca-Cola and Boeing have introduced initiatives into their workplaces (Bishnoi et al., 2012). Initiatives include the implementation of strategies that allow spiritual individuals to practice Bible, Quran or Torah study groups, to conduct voluntary prayer groups and interfaith dialogue groups, as well as meditation exercises.

Many traditional management approaches to addressing spirituality in the workplace have under-achieved, due to a dearth of empirical evidence particularly with respect to understanding individual spiritual needs (Jurkiewicz and Giacalone, 2004; Lund et al., 2003; Badrinarayanan and Madhavaram, 2008). However, as Helyer (2015) suggests, management will need to adjust their approach to their employees to ensure they understand there is an increased awareness between one's self and how this impacts upon their self-identity. For example, spirituality in the workplace is often seen as paradoxical. Managers often find the term ambiguous and highly nuanced (Richards et al., 2009) and organisations and individuals remain confused about the concept and its implications and often have little idea how to deal with or manage the phenomenon. Thus, managing spirituality and religious diversity is not straightforward, as it may not be feasible for an organisation to observe all spiritual practices or occasions. Nevertheless, the role of an organisation is seen as crucial to the development of employee spiritual needs (Samah's et al., 2012) and within this context spiritual leadership involves motivating and stimulating employees by instilling a vision and organisational culture based on altruistic values and policy (Mitchell and Beninger, 2015). In turn, such a context produces a highly enthused, committed and industrious workforce where most of the employees will have a sense of belonging (Singh and Mishra, 2016; Fry et al., 2017). A previous study by Reave (2005) suggested that the values of a leader have historically been viewed as spiritual ideals and include key traits such as integrity and humility, but have a very positive influence on the leadership success. In agreement, Kolodinsky et al. (2008) claim that organisational spirituality was found to be more positively related to job involvement, organisational identification and work satisfaction, and negatively related to organisational frustration. Therefore, business leaders who have attempted to provide goods and services that typically enhance quality of life often do this without considering the impact on the spiritual well-being of their employees and stakeholders, or even the broader community (Collins, 2010). Although, due to the individualised nature of spirituality, organisations can experience difficulty in demonstrating fairness and equality within a diverse workforce. In addition, employees' belonging to the same religion may exhibit significant differences in how they demonstrate or observe their beliefs. A topical example is taken from the English Premier Football League where Muslim players have demonstrated differing perspectives on whether to fast during match days during Ramadan (Cowling, 2013). As a result, employers can struggle to produce policies and procedures that support the complex spiritual requirements of employees.

As previously noted, there is a dearth of empirical research relating to spirituality in the workplace. Of the few studies there are, Digh (1999) and Pawar (2016) showed that, depending on their particular belief system, some employees felt that spirituality in the workplace was tolerated to different degrees. This finding was supported by Lips-Wiersma and Mills (2002) whose findings showed that 20 per cent of their US sample had been subjected to religious bias by having to use their holiday entitlement to observe significant dates in their own religious calendar, whilst Christian festivals such as Christmas and Easter were public holidays. On the other hand, research undertaken by Forstenlechner and Al-Waqfi (2010), suggested that these perceptions might be misplaced. Their study showed that the perceived view of Muslim workers in their study was that discrimination against 
JWAM

11,1

them existed within the workplace, whereas in reality employers in the study showed a high level of commitment to respecting the traditions and beliefs of Muslims with little discrimination against Muslim employees being apparent. However, the research by Weller et al. (2001) and Vlas (2017), which examined conflict and discrimination in the workplace as reported by members of different ethnic and religious groups, found that Muslims reported the highest level of such incidents, both in terms of the number of respondents indicating that unfair treatment was experienced, and the number reporting these incidents as frequent rather than occasional and the current climate of Islamophobia in many countries has continued to reflect this nearly two decades on (Mahr and Nadeem, 2019; Sekerka and Yacobian, 2018; Ali et al., 2015). Christians on the other hand were generally much less likely to report unfair treatment than Muslims, Sikhs and Hindus, and nearly all the unfairness they reported was occasional rather than frequent, which highlights recent research that echoes the contemporary issues of racial discrimination in the workplace (Wall et al., 2017). Nevertheless, it is interesting to note that black-led Christian organisations, Mormons and Jehovah's Witnesses, which are often seen as outside mainstream Christian traditions, were much more likely to report unfair treatment than those respondents belonging to what is often seen as more established traditions such as Roman Catholicism or Anglicanism (Weller et al., 2001).

Whilst these studies indicate that there are still many discrepancies between the experiences of employees in relation to their spirituality and experiences within the workplace, the need to reflect and consider the needs of individuals in order to enhance well-being within the workplace has seen a growing impetus. Furthermore, there are growing numbers of spiritual people who are beginning to speak out in the workplace, with employees pressing employers for greater freedom to express their spirituality (Wennes and Quinn, 2008; Zohar and Marshall, 2004; Ahmed and Omar, 2014). The Chartered Institute of Personnel and Development (CIPD) address this specifically by highlighting the need to invest in and engage with employees to embed the principles that good work is inclusive and good or well-being, supporting long-term benefits for individuals, organisations and society (CIPD, 2017). This focus upon investing in employees' well-being and furthering inclusivity within the workplace certainly provides scope for the consideration of the role employees' spirituality may play within this; however, the examination of spirituality within employee development remains underdeveloped (Dirkx, 2013). Research does highlight the links between workplace and developing one's sense of self (Lips-Wiersma and Mills, 2002; Lips-Wiersma and Morris, 2009), and Tennant (2012) identifies the forms of learning which bring about significant personal change with Budd (2011) linking the importance of this to the employees' sense of meaning and purpose within their work.

However, whilst workplace spirituality has gained some impetus the focus of this has shifted from the spirituality of the individual to the spirituality of the organisation, which is reflected in the culture of the organisation, and is often associated with the themes of tolerance, patience and interconnectivity with colleagues (Hassan et al., 2016). These are certainly worthy endeavours for the organisation; however, the research does not explore steps taken to embrace individual spirituality to enhance this sense of cultural identity (Miller and Ewest, 2015). Dirkx (2013) highlights this disparity further by stating that within the developing body of research exploring workplace spirituality, there remains limited focus upon work-based learning and this is reinforced further by the dearth in succeeding literature and the dominance of American research within what is still a narrow field. Whilst work-based learning can certainly benefit from a supportive organisational culture, the resources of the individual should not be ignored. Research into individual spirituality has highlighted clear strengths which can be drawn from an individual's spirituality (Falb and Pargament, 2014; Rye et al., 2013); nonetheless, drawing upon this to support employees' in either work or development opportunities remains under-researched. This article therefore 
considers the employees' perspectives upon individual spirituality and organisational culture before reflecting upon what this means for the work-based learner.

\section{Research methodology}

The research objectives of the current survey are; to examine whether spirituality is perceived as a source of conflict within the workplace; to examine whether respondents felt able to express their spiritual beliefs; to examine whether respondents felt able to observe their spiritual beliefs; and to examine the extent to which respondents felt that the organisation recognised their spirituality via its culture, dialogue, policies and procedures. The sampling unit was a multi-national retail United Kingdom (UK)-based organisation with an ethnically diverse national workforce. The study was tested by collecting data from managers and employees of this large multi-million pound retail chain organisation in the UK consisting of 55 stores and 1,249 employees. The self-developed questionnaires were sent through the internal e-mail (electronically) to the General Managers and Sales Managers who printed them off, completed theirs and then distributed the employee surveys to their respective staff. The questionnaires were only distributed to individuals who expressed some form of spirituality whether it be nihilistic, materialistic, humanistic or religious. (Kourie, 2006).

Spirituality can be polarised into two extreme views (Bhatia and Arora, 2017). First, the traditional perspective views religion as an expression of spirituality in search of the sacred, whilst the opposing of the continuum is represented by a humanistic view of spirituality, with little or no religious connotations (Fisher, 2011). The importance of spirituality can apply equally to those who do not identify with, or have a connection with organised religion, as much as to those who do (The Royal College of Psychiatrists, Spirituality and Mental Health, 2019). Therefore, every participant was given to opportunity to participate whether they regard themselves as religious or not. These were collected through the internal post in sealed envelopes (paper copies) provided by the research team. The questionnaire was developed incorporating a five-point Likert-scale items $(1=$ strongly disagree; $5=$ strongly agree) derived from the literature. The questionnaire was piloted on 30 employees of the organisation and a number of changes were made to the instrument based on their feedback, most notably reducing the seven-point scales to five-point scales. The questionnaires were then distributed to all 1,249 employees and 618 (49 per cent) usable questionnaires were returned.

\section{Results}

A Cronbach coefficient $\alpha$ reliability test for the sample was 0.804 and thus with a reliability score above 0.70 showing a high degree of consistency within the scale data, parametric and non-parametric analysis can be conducted.

\section{Sample profile: gender, age and religion}

The sample was comprised of 369 (59.7 per cent) males and 247 (39.3 per cent) females. In sum, 39 (0.63) of respondents were aged between 16 and 24; 123 (18 per cent) were aged between 25 and 34; 136 ( 22 per cent) between 35 and 44; 167 (27 per cent) between 45 and 54; and 151 (24 per cent) were aged 55 or above. Over 70 per cent of the sample described themselves as either Christians ( $n=330,53$ per cent) or Muslims ( $n=113,18$ per cent), with the remainder from other faiths including Sikhs and Jews.

The first section of the research instrument comprised nine scale items designed to measure respondents' awareness of organisational policies and procedures relating to spirituality that were not provided/in place in the organisation. The results are given in Table I. 
JWAM

11,1

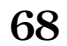

Table I.

Organisational policies and procedures in place within the organisation

\begin{tabular}{lcl}
\hline & Mean (SD) & $p$-value \\
\hline My organisation has a clear policy on ethnical, cultural and ethnic spiritual diversity & $3.26(1.41)$ & 0.001 \\
My organisation has a clear policy on spirituality & $1.07(1.19)$ & $0.000^{* * *}$ \\
I am aware of how my organisation's policies and procedures on spirituality influence & & \\
work on a day-to-day basis & $1.27(1.36)$ & 0.004 \\
I am aware of a health or wellness programme within my workplace & $3.91(1.15)$ & $0.002^{*}$ \\
I respect and comply with company procedures and rules whether they conform to my & & \\
personal values and beliefs or not & $3.74(1.02)$ & 0.000 \\
I am aware of work/life balance programme within my workplace & $1.76(1.26)$ & $0.000^{* *}$ \\
I am aware of counselling or psychotherapy within my workplace & $3.22(1.46)$ & 0.002 \\
I am offered flexitime within my workplace to fulfil my spirituality & $1.14(0.85)$ & 0.003 \\
I am aware of prayer or meditation group within my workplace & $2.12(1.12)$ & 0.001 \\
Notes: ANOVA significant at $* p<0.05 ; * p<0.01$ & & \\
\hline
\end{tabular}

What is most notable about the results presented for both scales is that religion was not a factor in individual responses. That is to say, respondents - whether Christian, Muslin, Sikh, Hindu or Jewish - were broadly in agreement on all of the scale items presented here.

The findings in Table I indicate that nine statements were statistically significant $(<p=0.000)$ is the strength of disagreement with the statements relating to the provision by the organisation of policies and procedures relating to spirituality and religion. This was most marked for items 2 (1.07), 3 (1.27), 6 (1.76), 8 (1.14) and 9 (2.12). Even the statement with the highest overall mean item 5 ("I am aware of a health or wellness programme within my workplace") at 3.91 merely indicates that respondents were unsure whether or not there was health or wellness provision within the company. Post hoc tests indicated that there were slight differences in responses by age cohorts, but these did not affect the overall results.

The second section of the research instrument comprised a further nine scale items designed to measure respondents' feelings about their own spirituality within the workplace. The results are presented below in Table II.

Table II shows that there are statistically significant differences amongst the statements surrounding spirituality and work $(p=0.004$ and below 0.05). The scale item with the highest level of agreement across the age groups was "Spirituality is a personal and individual matter and should not be discussed or practised in the workplace" (4.14). This correlated with the very low levels of disagreement with scale items 1 (2.08), 2 (2.07), 3 (1.27), 4 (1.91), 6 (2.58) and 9 (1.12). Again, there were some differences by age cohort to the scale item "Spirituality is a personal and individual matter and should not be discussed or practised in the workplace". The 55+ age group had the highest level of agreement (4.08)

\begin{tabular}{lcc}
\hline & Mean (SD) & $p$-value \\
\hline I have discussed my religion or spirituality with co-workers & $2.08(1.11)$ & 0.004 \\
Religion is an appropriate topic for discussion within the workplace & $2.07(0.69)$ & $0.001 *$ \\
Spirituality is an appropriate topic for discussion within the workplace & $1.27(0.65)$ & 0.001 \\
I feel comfortable discussing the topic of religion or spirituality at work & $1.91(1.59)$ & 0.002 \\
I feel comfortable discussing my own religion or spirituality at work & $3.74(1.02)$ & 0.000 \\
I feel spiritually fulfilled at work & $2.58(1.27)$ & $0.000 *$ \\
I feel that the level of spiritual fulfilment has a direct impact on my performance at work & $3.33(1.76)$ & 0.004 \\
Spirituality is a personal and individual matter and should not be discussed or practised & & \\
in the workplace & $4.14(1.85)$ & 0.001 \\
The workplace is incompatible with spirituality & $1.12(1.12)$ & 0.000 \\
Notes: ANOVA significant at $* p<0.05 ; * * p<0.01$ & &
\end{tabular}

The workplace is incompatible with spirituality
Table II.

Spirituality and work 
compared to the 35-44 year olds (3.50). However, scale item 5 ("I feel comfortable discussing the topic of religion or spirituality at work") showed that the 25-34 year olds (4.08) and the $55+(4.13)$ were more in agreement than the other age groups which were significantly different. The 45-54 cohort (2.43) responded most negatively to this scale item and was statistically different to all the other groups.

\section{Discussions and conclusions}

This paper investigated the extent to which employees felt they were under pressure to compromise their basic values at work, the policies and procedures in operation and the management support available on issues relating to employees' spirituality. The range of responses was generally consistent, with responses leaning more towards the strongly disagree end of the scale. As mentioned, probably the most striking aspect of the results was the consistency of response across all faith groups in the sample. This is in striking contrast to the results present by Digh (1999), Forstenlechner and Al-Waqfi (2010) and Weller et al. (2001). This contrast might be due to UK specific factors, but given that this is the first study of its kind in the UK, this is purely speculation.

The results also showed quite clearly that the sample were in no doubt that few, if any, organisational processes and procedures beyond the legislation provided for the purpose of equality and diversity had been put in place relating to either the practice of their religion or the nurturing of a broader spirituality. For those in the workplace, this suggests a potential gap in provision and clarity in workplace positioning. As previously discussed, spirituality as a term lacks clarity or a consensus on definition and as spirituality is considered a broad term with multiple interpretations, the reliance on equality and diversity policies and procedures, which are fundamentally underpinned by relevant legislation could be deemed as to narrow a perspective to support the spiritual needs of the employee. Where queries and requirements fall outside of the scope of existing policies and procedures, it must be questioned as to how employers and employees navigate through the unchartered grey area that is encompassed by the individual spiritual needs of the employee. Certainly, the limitations of current policies and procedures suggested by the current research intimate that this may come down to the ability of individual employers and employees to drive this forward on a case by case basis. However, in such instances, the skills and personal attributes of the individual to lead on this, together with the relationships between employees and managers and positioning within the company could all have an impact upon the potential to reach a satisfactory outcome for all parties. The psychology behind such interactions is something which would benefit from further exploration as well as further research into specific case studies of incidents which have occurred in relation to spirituality where no definitive policy was in place to examine both the approach taken and eventual outcomes.

There was also a general consensus that across a wide range of responses that the workplace was incompatible with overt displays of spirituality or religion. What little differences in response there were across a range of scale items related to age rather than religion, which is somewhat surprising. What is more unexpected is that there seemed to be no logic to which age cohorts differed; agreement/disagreement with a specific scale item might have been expected to progress through contiguous age cohorts, but this was not the case with the research reported here. The psychology behind responses is something which would benefit from further research. There are many factors which may influence responses in relation to age but the surprising feature of the current research is the lack of consistency between consecutive age groups. Where responses appear consistent within groups but with no discernible pattern between different age groups exist, the opportunity to complete qualitative research may provide some further clarity. Additional research within other organisations would also be of benefit as this would potentially allow for comparisons between data sets to be drawn and would potentially support an understanding of whether

Work-based learners 
JWAM

11,1

the age-related responses were specific to the organisational culture experienced by respondents within the current study or something which could be attributed to wider external factors which also impact on employees' perspectives.

\section{Practical impact upon work-based learners}

The development of spiritual awareness across a wider community has produced a series of changes and aroused academic and practitioner interest in management (Baker et al., 2011). However, because of the dominance and influence of modernisation for much of the twentieth century, there has been a tendency to show corporations as being preoccupied with a range of performance metrics such as profit, turnover and market dominance. Throughout management discourse, performance metrics are often termed as the minimum expectation of the organisation. These dimensions and their effective management are important in the running of any operation, but it is equally recognised that it is important to pay due diligence to what are called the soft factors in business, which includes human resources management (Stokes, 2011). Therefore, for an organisation to continually succeed and prosper in today's harsh economic climate it is important that the moral and ethical strategies promote its foundations. Consequently, where the data indicate that spirituality is not factored into organisational policies and procedures specifically and provide clear consensus of this across religious groups, it must be questioned as to what this means for the learning self (Tennant, 2012). Literature has highlighted intrinsic links between ones' self of self and fulfilment at work (Lips-Wiersma and Morris, 2009) and the renowned professional body for personnel and development highlights the importance of investing in employees individual needs and well-being (CIPD, 2017). Although the term spirituality is clouded by the lack of consensus on definition, there is a thread which implicitly links spirituality with well-being (Fisher, 2011). If spirituality is to be considered an internalised framework which underpins sense of self (Dirkx, 2013) then this will undoubtedly influence employee engagement with development opportunities. Furthermore, for work-based learners to be successful in their development, they must draw upon an internal skills such as resilience (Youssef and Luthans, 2007), which can be drawn from an individual's spirituality (Kim and Esquivel, 2011). The data demonstrates limited awareness of how organisational policies in relation to spirituality influence work on a day to day basis and this could be argued to in part be influenced by that lack of clear attention given to spirituality within underlying policies and procedures. Where employees are unable to identify or apply their spirituality to their day to day work, this could restrict the opportunities to utilise their spirituality as a resource to support them in development opportunities. Consequently, further consideration of how to recognise and embed opportunities to draw upon employees' spirituality within work-based learning should be considered.

One notable oversight suggested by the data is the provision of specific programmes and spaces deigned to support the employees' work/life balance (Matthieu, 2017). The current research demonstrates little awareness of work/life balance programmes amongst employees and little acknowledgement of flexitime to observe spiritualty and limited awareness of practical spaces in which to explore spirituality such as prayer or mediation rooms. When taken in consideration of the potential benefits to work-based learners in drawing upon their spirituality to support them both within day to day work and development activities, it is perhaps surprising that the difficulties experienced by employees engaged in work-based learning, as opposed to more traditional firms of study, have not yet been acknowledged sufficiently to trigger development of a supporting programme or framework. The additional time considerations for work-based learners maybe considered in relation to their role, however, time for employees to recharge or draw upon spirituality for support (James, 2014) or utilise specific spaces within the workplaces for this purpose (Shanafelt et al., 2012) is not currently available or promoted. Further research in relation to this would be required in order 
to determine the exact nature of the current provision with data highlighting only employees' limited awareness and/or engagement with it.

Within the data, there is also disparity between the perceptions of employees in relation to how spirituality links to the workplace. Respondents indicated that spirituality was an inappropriate topic for discussion at work and identified that they uncomfortable discussing aspects of their spirituality with co-workers. This was further reinforced by the consensus that spirituality is an individual matter and should not be explored or practiced within the workplace yet this contrasts with the high number of respondents stipulating that felt the workplace was not incompatible with spirituality. The juxtaposition between these statements is striking. Certainly, the compatibility of spirituality and work is something which is recognised by literature (Dirkx, 2013; Lips-Wiersma and Morris, 2009) and the benefits to supporting individuals and investing in the well-being of employees is encouraged (CIPD, 2017), yet there is a clear disconnect between these concepts and employees practical experiences of sharing and drawing upon their spirituality within workplace interactions. Wider recognition of the role employee spirituality can play in supporting work-based learners, in conjunction with policies and processes to facilitate this and further embed the relationship between spirituality and development within organisational discourse could create additional benefits for employees' and the development as learners, although the extent of this does require further research.

In conclusion, while the data showed clear evidence that there is a relatively negative perception towards how spirituality can link in with work, with little acknowledgement regarding any potential benefits within the workplace, much more research, both quantitative and qualitative is required. This is the first study of its kind to be undertaken within the UK, and one of only a handful of studies globally and, as with all pioneering studies, it raises a host of questions that cannot be addressed by the results presented here. There is certainly scope to conduct similar studies in other countries for comparative purposes; as indicated by the literature, research is dominated by an American perspective and so a similar study in America could contribute to the broader evidence base which exists there. However, exploring the comparisons with other Western countries which could allude to similar multi-cultural workplace dynamics would provide further contribution to the field by expanding upon the data available and offering a more global perspective than is currently available. Another exciting direction for future research would also be the opportunity to investigate an organisation operating in both secular and non-secular countries would provide in greater scope for discussion offering a clear comparison between employees working within the same organisation with potentially contrasting religious and spiritual perspectives offers further scope for providing both breadth and depth of understanding on the topic.

\section{Limitations/implications}

The authors acknowledge that this is an extremely sensitive topic and an emergent study based on one organisation in the UK. We do not claim that all our findings are generalisable to all workplaces. Notwithstanding this, it is a pioneering study that raises a host of questions that cannot be addressed by the results presented here. The research questions in this study were deliberately designed to take a broad perspective - future qualitative research could explore these views more deeply. In addition, the broad context of questions such as spiritual diversity as a policy may not have been fully understood by the employees. There is a need for more research, both quantitative and qualitative, for example, examining the possible link between spiritual fulfillment and productivity. Furthermore, the questionnaires used a convenience sampling technique rather than randomly sampling the whole population and responses given may not provide a full representation of all employees' perspectives towards spirituality within the study organisations. 
JWAM

11,1

The responses from across the groups suggest that employees would like organisations to support their personal spirituality providing equitable practice through policies. There is a substantial gap between substantive actions and the preferences of the employees. Organisations have not moved forward on how to respond to the growing presence of spirituality in the workplace and the working concept of spirituality remains vague, complicated, and vastly ineffective (Dirkx, 2013). This is possibly not surprising considering how complex individual spirituality can be. Moreover, historical attempts to define spirituality by how it is perceived from an organisational viewpoint have represented a considerable hurdle, which has complicated policy making (Khaled et al. 2012; Sekerka, and Yacobian, 2018). Nevertheless, management are missing the opportunity to benefit from positive values and meet the core needs of the workplace by not developing spiritual policies (Mitchell and Beninger, 2015). Furthermore, in light of a fragile society that is characterised by such regrettable features as terror attacks (some of which are deemed to be in the name of religion), increased globalisation and a post-Brexit discriminatory environment, the authors would suggest that spirituality in the workplace is indeed both important and relevant (Vlas, 2017).

\section{References}

Ahmed, A. and Omar, Z. (2014), "Reducing deviant behaviour through workplace spirituality and job satisfaction”, Asian Social Science, Vol. 10 No. 19, pp. 107-112.

Alas, R. and Mousa, M. (2016), "Organizational culture and workplace spirituality", International Journal of Emerging Research in Management and Technology, Vol. 5 No. 3, pp. 1-9.

Ali, S.R., Yamada, T. and Mahmood, A. (2015), "Relationships of the practice of hijab, workplace discrimination, social class, job stress, and job satisfaction among Muslim American women", Journal of Employment Counseling, Vol. 52 No. 4, pp. 146-157.

Badrinarayanan, V. and Madhavaram, S. (2008), "Workplace spirituality and the selling organization", Journal of Personal Selling and Sales Management, Vol. 24 No. 4, pp. 421-434.

Baker, C., Stokes, P., Lichy, J., Atherton, J. and Moss, D. (2011), "Values, beliefs and attitudes in the era of late capitalism: a consideration of the re-emergence and re-positioning of faith and spirituality as spiritual capital in the workplace", available at: http://ecoles-idrac.academia.edu/JessicaLichy/Papers/1720140/ Values_Beliefs_and_Attitudes_in_the_Era_of_Late-Capitalism_A_Consideration_of_the_ReEmergence_and_Re-Positioning_of_Faith_and_Spirituality_as_Spiritual (accessed 17 June 2019).

Bell, E. and Burack, S. (2001), "A rumour of angels': researching spirituality and work organizations", Academy of Management Proceedings, pp. 1-7.

Bhatia, S. and Arora, E. (2017), "Workplace spirituality: an employer-employee perspective", International Journal of Innovate Research and Development, Vol. 6 No. 1, pp. 106-111.

Bishnoi, N.K., Gupta, S. and Mathews, C. (2012), "Workplace spirituality and Indian ethos", Purushartha, Vol. 14 No. 2, pp. 1-13.

Budd, J.W. (2011), The Thought of Work, Cornell University Press, MN.

Cavanagh, G F. (1999), "Spirituality for managers: context and critique", Journal of Organizational Change Management: Spirituality in the Workplace, Vol. 12 No. 3, pp. 186-199.

CIPD (2017), The Manifesto for Work, Chartered Institute of Personnel and Development, London.

Collins, D. (2010), "Designing ethical organizations for spiritual growth and superior performance: an organization systems approach", Journal of Management, Spirituality and Religion, Vol. 7 No. 2 , pp. 95-117.

Cowling, R. (2013), "BBC sport: premier league: how Muslims are changing English football culture", available at: www.bbc.co.uk/sport/0/football/23159023 (accessed 14 June 2019).

Deshpande, A. (2012), "Workplace spirituality, organizational learning capabilities and mass customization: an integrated framework", International Journal of Business and Management, Vol. 7 No. 5, pp. 3-18. 
Digh, P. (1999), "Religion in the workplace: make a good-faith effort to accommodate", HR Magazine, Vol. 43 No. 13, pp. 84-91.

Dirkx, J.M. (2013), "Leaning in and leaning back at the same time: toward a spirituality of work-related learning", Advances in Developing Human Resources, Vol. 15 No. 4, pp. 356-369.

Falb, M.D. and Pargament, K.I. (2014), "Religion, spirituality, and positive psychology: Strengthening wellbeing", in Pedrotti, J.T. and Edwards, L.M. (Eds), Perspectives on the Intersection of Multiculturalism and Positive Psychology, Springer, Athens, pp. 143-157.

Fisher, J. (2011), "The four domains model: connecting spirituality, health and well-being”, Religious Journal, Vol. 2 No. 1, pp. 17-28.

Forstenlechner, I. and Al-Waqfi, M.A. (2010), "A job interview for Mo, but none for Mohammed: religious discrimination against immigrants in Austria and Germany", Personnel Review, Vol. 39 No. 6, pp. 767-784.

Fry, L.W., Latham, J.R., Clinebell, S.K. and Krahnke, K. (2017), "Spiritual leadership as a model for performance excellence: a study of Baldrige award recipients", Journal of Management, Spirituality and Religion, Vol. 14 No. 1, pp. 22-47.

Hassan (2016), "Impact of workplace spirituality on job satisfaction: mediating effect of trust", Cogent Business, Vol. 3 No. 1, pp. 1-15.

Hassan, M., Bin Nadeem, A. and Akhter, A. (2016), "Impact of workplace spirituality on job satisfaction: mediating effect of trust", Cogent Business and Management, Vol. 3 No. 1, pp. 1-15.

Helyer, R. (2015), "Learning through reflection: the critical role of reflection in work-based learning (WBL)", Journal of Work-Applied Management, Vol. 7 No. 1, pp. 15-27.

Hofstede, G. (1997), Cultures and Organizations, McGraw-Hill, New York, NY.

James, A. (2014), "Work-life 'balance', recession and the gendered limits to learning and innovation (or, why it pays employers to care)", Gender, Work and Organization, Vol. 21 No. 3, pp. 273-294.

Jurkiewicz, C.L. and Giacalone, R.A. (2004), "A values framework for measuring the impact of workplace spirituality on organizational performance”, Journal of Business Ethics, Vol. 49 No. 2, pp. 129-142.

Khaled, M.T., Banyhamdan, H.H. and Mohi-Adden, Y.A. (2012), "Transforming an organization into a spiritual one: a five-pathway integrated framework", International Journal of Business and Management, Vol. 7 No. 11, pp. 74-83.

Kim, S. and Esquivel, G.B. (2011), "Adolescent spirituality and resilience: theory, research, and educational practices", Psychology in the Schools, Vol. 48 No. 7, pp. 755-765.

Kolodinsky, R., Giacalone, R.A. and Jurkiewicz, C.L. (2008), "Workplace values and outcomes: exploring personal, organizational and interactive workplace spirituality", Journal of Business Ethics, Vol. 81 No. 2, pp. 465-480.

Kourie, C. (2006), “The 'turn' to spirituality”, Journal of Acta Theologica Supplementum, Vol. 8 No. 1, pp. 19-38.

Lips-Wiersma, M. and Mills, C. (2002), "Coming out of the closet: negotiating spiritual expression in the workplace", Journal of Managerial Psychology, Vol. 17 No. 3, pp. 183-202.

Lips-Wiersma, M. and Morris, L. (2009), "Discriminating between 'meaningful work' and the 'management of meaning'", Journal of business Ethics, Vol. 88 No. 3, pp. 491-511.

Lund, D.K., Fornaciari, C.J. and McGee, J.J. (2003), "Research in spirituality, religion and work: walking the line between relevance and legitimacy", Journal of Organizational Change Management, Vol. 16 No. 4, pp. 378-395.

Mahr, F. and Nadeem, T. (2019), "Muslim women and Islamophobia", Islamophobia and Psychiatry, Springer Nature Switzerland, Cham, pp. 295-305.

Matthieu, F. (2017), "The failure of state multiculturalism in the UK? An analysis of the UK's multicultural policy for 2000-2015”, Ethnicities, pp. 1-27, doi: 10.1177/1468796817713040.

Miller, D.W. and Ewest, T. (2015), "A new framework for analyzing organizational workplace religion and spirituality", Journal of Management, Spirituality and Religion, Vol. 12 No. 4, pp. 305-328. 
JWAM

11,1

Miller, W.R. and Thoresen, C.E. (2003), "Spirituality, religion and health: an emerging research field", American Psychologist, Vol. 58 No. 1, pp. 24-35.

Mitchell, M. and Beninger, K. (2015), Religion or Belief in the Workplace and Service Delivery - Findings from a Call for Evidence. NatCen Social Research, Equality and Human Rights Commission, London.

Mitchell, R.K. (2013), "Spiritual identity, stakeholder attributes and family business workplace spirituality stakeholder salience", Journal of Management, Spirituality and Religion, Vol. 10 No. 3, pp. 1-38.

Pawar, B.S. (2016), "Workplace spirituality and employee well-being: an empirical examination", Employee Relations, Vol. 38 No. 6, pp. 975-994.

Ramdass, P. and Van Tonder, C.L. (2009), "A spirited workplace: employee perspectives on the meaning of workplace spirituality", SA Journal of Human Resource Management, Vol. 7 No. 1, pp. 230-241.

Reave, L. (2005), "Spiritual values and practices related to leadership effectiveness", The Leadership Quarterly, Vol. 16 No. 5, pp. 655-687.

Richards, P.S., Bartz, J.D. and O'Grady, K.A. (2009), "Assessing religion and spirituality in counselling: some reflections and recommendations", Counselling and Values, Vol. 54 No. 1, pp. 65-79.

Rye, M.S., Wade, N.G., Fleri, A.M. and Kidwell, J.E. (2013), "The role of religion and spirituality in positive psychology interventions", APA Handbook of Psychology, Religion, and Spirituality, American Psychological Association, pp. 481-508.

Samah, S.A., Silong, A.D., Jusoff, K. and Ismail, I.A. (2012), "Relationship between spirituality and academic leader effectiveness", International Conference on Human and Social Sciences, 6, pp. 1-270.

Sedikides, C. (2010), "Why does religiosity persist?”, Personality and Social Psychology Review, Vol. 14 No. 1, pp. 3-6.

Sekerka, L.E. and Yacobian, M.M. (2018), "Fostering workplace respect in an era of anti-Muslimism and Islamophobia: a proactive approach for management", Equality, Diversity and Inclusion: An International Journal, Vol. 37 No. 8, pp. 813-831.

Shanafelt, T.D., Boone, S., Tan, L., Dyrbye, L.N., Sotile, W., Satele, D., West, C.P., Sloan, J. and Oreskovich, M.R. (2012), "Burnout and satisfaction with work-life balance among US physicians relative to the general US population”, Archives of Internal Medicine, Vol. 172 No. 18, pp. 1377-1385.

Singh, S. and Mishra, P. (2016), "A review on role of spirituality at workplace", The International Journal of Indian Psychology, Vol. 3 No. 3, pp. 1-6.

Stokes, P. (2011), Critical Concepts in Management and Organization Studies, Palgrave Macmillan, Basingstoke.

Tennant, M. (2012), The Learning Self: Understanding the Potential for Transformation, John Wiley and Sons, Sydney.

The Royal College of Psychiatrists, Spirituality and Mental Health (2019), "Spirituality and mental health", available at: www.rcpsych.ac.uk/mentalhealthinformation/therapies/ spiritualityandmentalhealth.aspx (accessed 17 June 2019).

Vlas, N. (2017), "Is Religion inherently violent? Religion as a threat and promise for the global security", Politics and Religion Journal, Vol. 2 No. 4, pp. 297-314.

Wagner-Marsh, F. and Conley, J. (1999), "The fourth wave: the spiritually-based firm”, Journal of Organizational Change Management, Vol. 12 No. 4, pp. 292-301.

Wall, T. (2017), "A Manifesto for higher education, skills and work based learning: through the lens of the manifesto for work", Journal of Higher Education, Skills and Work Based Learning, Vol. 7 No. 3, pp. 304-314.

Wall, T. and Knights, J. (2013), Leadership Assessment for Talent Development, Kogan, London.

Wall, T., Tran, L.T. and Soejatminah, S. (2017), "Inequalities and agencies in workplace learning experiences: international student perspectives", Vocations and Learning, Vol. 10 No. 2, pp. 141-156. 
Weller, P., Feldman, A. and Purdam, K. (2001), Home Office Research Study 220: Religious Discrimination in England and Wales, Home Office Research, Development and Statistics Directorate, London, pp. 1-197.

Wennes, B. and Quinn, B. (2008), "Mind-sets, mirrors and mid-career education”, International Journal of Public Sector Management, Vol. 21 No. 4, pp. 353-367.

Youssef, C.M. and Luthans, F. (2007), "Positive organizational behavior in the workplace: The impact of hope, optimism, and resilience", Journal of Management, Vol. 33 No. 5, pp. 774-800.

Zohar, D. and Marshall, I. (2004), Spiritual Capital: Wealth We Can Live By, Bloomsbury, London.

\section{Further reading}

Ali, A.J. (2010), "Islamic challenges to HR in modern organizations", Personnel Review, Vol. 39 No. 6, pp. 692-711.

Benefiel, M. (2007), "Pathfinders and trailblazers. Exploring the territory of spirituality in organizations", Managerial Finance, Vol. 33 No. 12, pp. 947-956.

Biagini, A., Carteny, A., Vagnini, A. and Motta, G. (2012), "Proceedings of the $2^{\circ}$ international conference on human and social sciences", International Scientific Committee ICHSS 2012, MCSER Publishing, Vol. 32 No. 6, pp. 1-270.

Easterby-Smith, M., Thorpe, R. and Lowe, A. (2002), Management Research an Introduction, 2nd ed., Sage Publications, London.

Jones, M.D. (2006), "Job satisfaction or life satisfaction", Journal of Behavioural and Applied Management, Vol. 8 No. 1, pp. 20-42.

Karakas, F. (2010), "Spirituality and performance in organizations: a literature review", Journal of Business Ethics, Vol. 94 No. 1, pp. 89-106.

Lowe, J. and Gayle, V. (2007), "Exploring the work/life/study balance: the experience of higher education students in a Scottish further education college", Journal of Further and Higher Education, Vol. 31 No. 3, pp. 225-238.

Marques, J.F. (2005), “The spiritual worker”, Journal of Management Development, Vol. 25 No. 9, pp. 884-895.

Neck, C.P. and Milliman, J.F. (1994), "Thought self-leadership finding spiritual fulfilment in organizational life", Journal of Managerial Psychology, Vol. 9 No. 6, pp. 9-16.

\section{Corresponding author}

Scott Foster can be contacted at: S.Foster@ljmu.ac.uk

For instructions on how to order reprints of this article, please visit our website:

www.emeraldgrouppublishing.com/licensing/reprints.htm

Or contact us for further details: permissions@emeraldinsight.com 